\title{
Malignant tumours of temporomandibular joint
}

\author{
Feiluore Yibulayin ${ }^{1,2+}$, Chen-xi Yu ${ }^{1,3+}$, Lei Feng ${ }^{1}$, Meng Wang ${ }^{1}$, Meng-meng Lu', Yuan Luo ${ }^{1}$, Hui Liu', \\ Zhi-cheng Yang ${ }^{1 *}$ and Alimujiang Wushou ${ }^{1 *}$
}

\begin{abstract}
Background: Malignant tumours of the temporomandibular joint (MTTMJ) are extremely rare. Studies describing its unique epidemiology, clinicopathological features, treatment and prognosis comprehensively are limited. To address these issues, current investigation was performed.

Methods: A retrospective research was carried out by using population-based data from the Surveillance, Epidemiology, and End Results database (1973-2016).

Results: Data for a total of 734 patients, including 376 men and 358 women, was found. The median age was 47 years. The 5-year and 10-year disease specific survival (DSS) rates were 69.2 and 63.6\%, respectively. Significant differences in DSS were found according to age, race, tumour type, AJCC/TNM stage, surgery, radiotherapy, chemotherapy and different treatment modalities $(P<0.05)$. In the multivariate survival analysis, age $>44$ years and AJCC stage III and IV were associated with poor DSS.
\end{abstract}

Conclusion: MTTMJ was mostly found in white people with a median age of 47 years without any sex predominance. Patient's age and AJCC stage was independent predictor of DSS.

Keywords: Temporomandibular joint, Malignant tumour, SEER analysis

\section{Background}

Temporomandibular joint (TMJ) disorders are very common and can be easily diagnosed $[1,2]$. However, malignant tumours of the temporomandibular joint (MTTMJ) are very rare and often cause facial asymmetry deformity and occlusal disorders [3]. MTTMJ originates from three possible sites: (a) intrinsic tissue of the TMJ, (b) extension of malignant tumours from adjacent issues, such as parotid gland malignant neoplasm, and (c) distant metastatic spread to the joint. Among these tumours, primary tumours from intrinsic tissue of the

\footnotetext{
* Correspondence: Zhicheng_yang1998@Fufudan.edu.cn; 505554273@qq.com

${ }^{\dagger}$ Feiluore Yibulayin and Chen-xi Yu contributed equally to this work. 'Department of Oral \& Maxillofacial Surgery and Oral Biomedical Engineering Laboratory Shanghai Stomatological Hospital Fudan University, 356 Beijing East Road, Shanghai 200001, People's Republic of China

Full list of author information is available at the end of the article
}

TMJ are extremely rare. MTTMJ patients may present with complex signs and symptoms that mimic those of myofascial pain and dysfunction syndrome, such as TMJ disorders [4]. As a result, the clinical manifestation and differential diagnosis of TMJ malignancies is challenging for primary care doctors [5].

Early diagnosis and treatment are important in achieving good prognosis in MTTMJ patients. As it is a solid tumour, surgical resection is the most important treatment modality for MTTMJ, and chemoradiotherapy is given as adjuvant therapy for advanced stage tumours and metastatic disease [6]. Surgical reconstruction of the TMJ is difficult, and poor treatment could result in loss of function, disfigurement, occlusal disorders and psychosocial morbidities [7]. To date, there are over 1000 reports regarding TMJ malignancy in PubMed [8].

(c) The Author(s). 2020 Open Access This article is licensed under a Creative Commons Attribution 4.0 International License, which permits use, sharing, adaptation, distribution and reproduction in any medium or format, as long as you give appropriate credit to the original author(s) and the source, provide a link to the Creative Commons licence, and indicate if changes were made. The images or other third party material in this article are included in the article's Creative Commons licence, unless indicated otherwise in a credit line to the material. If material is not included in the article's Creative Commons licence and your intended use is not permitted by statutory regulation or exceeds the permitted use, you will need to obtain permission directly from the copyright holder. To view a copy of this licence, visit http://creativecommons.org/licenses/by/4.0/. The Creative Commons Public Domain Dedication waiver (http://creativecommons.org/publicdomain/zero/1.0/) applies to the data made available in this article, unless otherwise stated in a credit line to the data. 
However, case reports and reviews accounted for the majority of these studies $[9,10]$.

Because MTTMJ is rare, there is lack of instructive data to characterize its unique epidemiology, clinicopathological features, treatment and prognosis comprehensively. A nationwide population-based cohort may provide an opportunity to address these issues. Thus, we performed current retrospective analysis by using data from the Surveillance, Epidemiology, and End Results (SEER) database (1973-2016).

\section{Methods}

\section{Data extraction}

SEER*Stat software was applied for data extraction (https://seer.cancer.gov, version 8.3.6). Primary MTTMJ cases were identified by using International Classification of Diseases for Oncology (ICD-O-3) topographic codes C41.1-mandible with bones and joints. The variables for analysis included pathological tumour types, age at diagnosis, sex, race, pathological differentiation, American Joint Committee on Cancer (AJCC) stage, treatment modalities, vital status and follow-up time. Our study used established data and did not involve interactions with human subjects. Therefore, institutional review board approval was not required.

\section{Statistical analysis}

Statistical analysis was performed by using the statistical packages $\mathrm{R}$ (The $\mathrm{R}$ foundation, http://www.r-project.org, version 3.4.3), Empower $\mathrm{R}$ (http://www.empowerstats. com, Boston, Massachusetts), and Statistical Package for Social Sciences (SPSS, Chicago, IL, Version 23.0 for Windows). Student's t-test or the non-parametric Wilcoxon test were used for numerical variable evaluation, and the categorical variables were compared with the chi-square test or Fisher's exact test. Kaplan-Meier survival analysis was used to assess overall survival (OS) and disease-specific survival (DSS). Prognostic factors were determined using the Cox multivariant regression model. $P$ values were considered statistically significant when $P<0.05$.

\section{Results}

\section{Summary statistics for the total study population}

A total of 734 primary cases were identified in the SEER database. The sex distribution was nearly equal with 376 males and 358 females. The median follow-up time period was 58 months (range, 0-499 months). MTTMJ mostly occurred in white people (70.3\%, 516/734). MTTMJ was distributed across all ages, and the median age was 47 years. There were more than 40 different pathological tumour types (Fig. 1). The top three pathological types were osteosarcoma (149 cases), malignant ameloblastoma (132 cases) and squamous cell carcinoma
(115 cases). Surgery was the mainstay treatment, and 562 patients received surgery. The summary of the study cohort's clinicopathologic characteristics is presented in Table 1.

\section{OS analysis}

The 3-year, 5-year and 10-year OS rates were 72, 65 and $55 \%$, respectively. The 5 -year OS was $78.4 \%$ for patients treated by surgery only, $61 \%$ for those who received both surgery and radiotherapy and 54\% for others combined with surgery and chemoradiotherapy. Significant OS differences were identified depending on age at diagnosis $(P<0.0001)$, race $(P=0.002)$, tumour type $(P<0.0001)$, AJCC T category $(P=0.0007)$, AJCC N category $(P<0.0001)$, AJCC $M$ category $(P<0.0001)$, AJCC stage $(P<0.0001)$ and treatment modality $(P<0.0001)$ (Fig. 2$)$. The Cox proportional hazards regression model was constructed to evaluate predictors of OS via multivariate survival analysis. Age $>47$ years $[\mathrm{HR}(95 \% \mathrm{CI})=2.76$ (1.15-6.65), $P=0.024$, age $\leq 47$ years as the reference value $]$ and AJCC M1 category $\left[\begin{array}{lll}\mathrm{HR} & (95 \% & \mathrm{CI}\end{array}\right)=$ 36.91(5.58-118.35), $P=0.024$, AJCC M0 stage as the reference value] were independently associated with worse OS.

\section{DSS analysis}

In the survival analysis for DSS, the 3-year, 5-year and 10-year DSS rates were 74.7, 69.2 and $63.6 \%$, respectively. Similarly, patients who received surgical treatment only had an $82 \%$ 5-year DSS rate; the 5-year DSS rate was $63 \%$ for those who received surgery plus radiotherapy and $55.3 \%$ for those who received surgery and chemoradiotherapy. Statistically significant survival differences were found among different treatment modalities $(P<0.0001)$. We also identified significant differences in DDS based on age range at diagnosis $(P<0.0001)$, median age $(P<0.0001)$, race $(P=0.0091)$, pathological tumour type $(P<0.0001)$, AJCC T category $(P<0.0001)$, AJCC N category $(P<0.0001)$, AJCC M category $(P<0.0001)$, AJCC stage $(P<0.0001)$, surgery $(P<0.0001)$, radiotherapy $(P<0.0001)$ and chemotherapy $(P=0.0028)$ (Fig. 3$)$. Age $>44$ years $[\mathrm{HR}(95 \% \mathrm{CI})=$ $2.72(1.23-5.97), P=0.013$, age $\leq 44$ years as the reference value] and AJCC stage III and IV [HR (95\% CI) = 19.85 (5.6-70.34), $P<0.0001$; HR (95\% CI) = 7.1 (1.34737.62), $P=0.021$, AJCC stage I as the reference value] were adversely associated with DSS.

\section{Discussion}

Apart from single case reports and small retrospective case series, there are insufficient data to characterize the demographic features of MTTMJ. Generally, the average age range of most patients with solid malignancies in the head and neck is $60-70$ years [11]. The typical incidence 


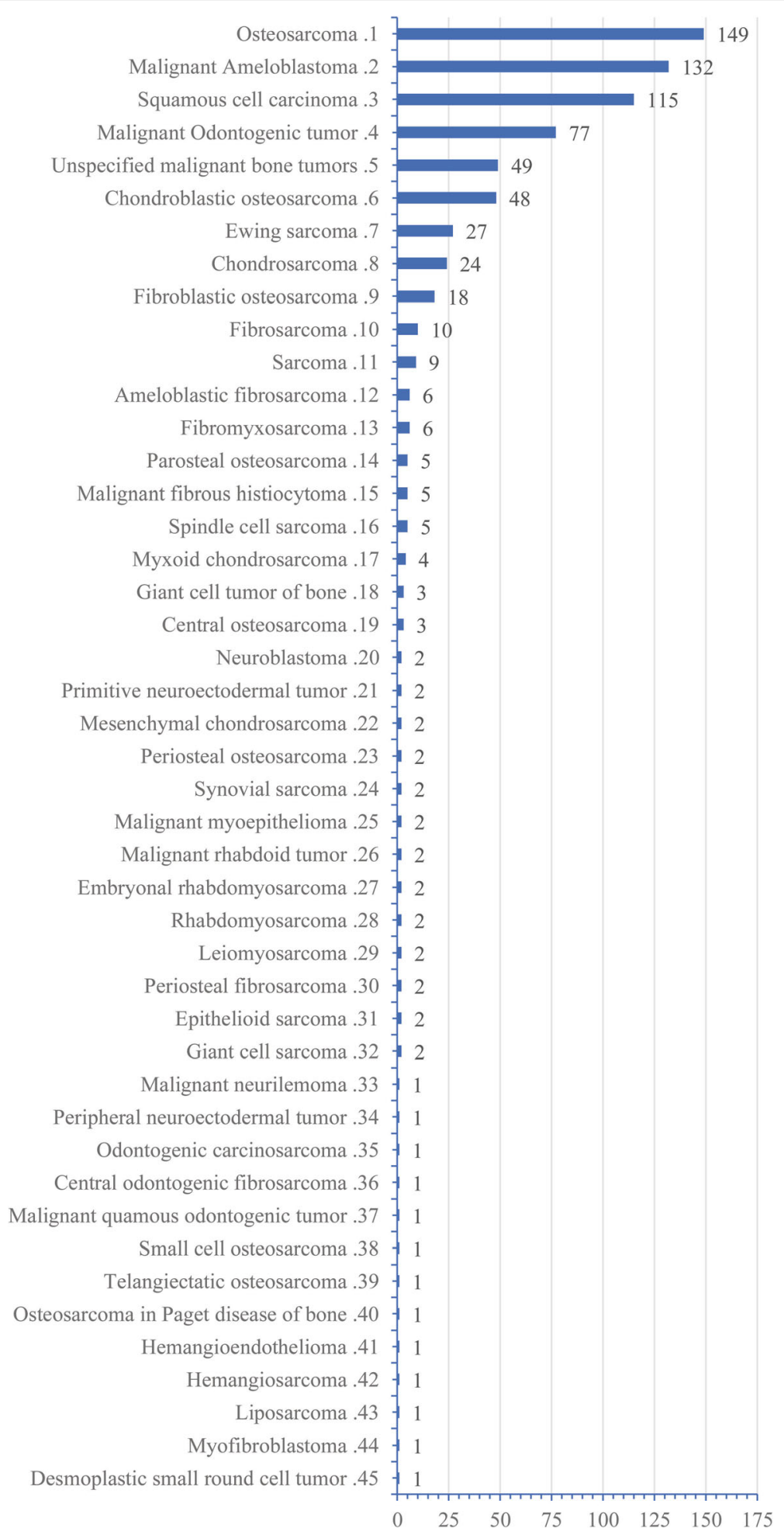

Fig. 1 The tumor types of TMJ registered in the SEER database

of MTTMJ occurred in the age range of 40-60 years old in most previous reports [7, 12-15]. The current study results show that the MTTMJ was almost evenly distributed among all age groups, with a median age of 47 years, and the sex ratio of males to females was close to 1:1. Previous MTTMJ studies were mainly based on a single center's institutional experience. The biggest disadvantage of these studies is that the sample size is too 
Table 1 The summary of MTTMJ patients' clinico-pathologic characteristics

\begin{tabular}{|c|c|c|c|c|c|c|}
\hline \multirow[t]{2}{*}{ Variables } & \multicolumn{3}{|c|}{ Disease specific survival $(n=611)$} & \multicolumn{3}{|c|}{ Overall survival $(n=734)$} \\
\hline & Alive (\%) & Dead (\%) & $P$-value & Alive (\%) & Dead (\%) & $P$-value \\
\hline \multicolumn{7}{|l|}{ Gender } \\
\hline Female & $198(64.7 \%)$ & $108(35.3 \%)$ & 0.67 & 199 (55.6\%) & 159 (44.4\%) & 0.711 \\
\hline Male & $203(66.6 \%)$ & $102(33.4 \%)$ & & $203(54 \%)$ & $173(46 \%)$ & \\
\hline \multicolumn{7}{|l|}{ Age } \\
\hline$\leq 44(47)$ & $272(81 \%)$ & $64(19 \%)$ & 0.000 & $272(74.9 \%)$ & $91(25.1 \%)$ & 0.000 \\
\hline$>44(47)$ & $129(46.9 \%)$ & $146(53.1 \%)$ & & $130(35 \%)$ & $241(65 \%)$ & \\
\hline \multicolumn{7}{|l|}{ Age period } \\
\hline 0-19 & $84(83.2 \%)$ & $17(16.8 \%)$ & 0.000 & $84(77.1 \%)$ & $25(22.9 \%)$ & 0.000 \\
\hline $20-29$ & $78(83.9 \%)$ & $15(16.1 \%)$ & & $78(79.6 \%)$ & $20(20.4 \%)$ & \\
\hline $30-39$ & $69(80.2 \%)$ & $17(19.8 \%)$ & & $69(74.2 \%)$ & $24(25.8 \%)$ & \\
\hline $40-49$ & $55(75.3 \%)$ & $18(24.7 \%)$ & & $55(65.5 \%)$ & $29(34.5 \%)$ & \\
\hline $50-59$ & $55(66.3 \%)$ & $28(33.7 \%)$ & & $55(36.4 \%)$ & $46(45.5 \%)$ & \\
\hline $60-69$ & $36(49.3 \%)$ & $37(50.7 \%)$ & & $36(36.4 \%)$ & $63(63.6 \%)$ & \\
\hline $70-79$ & 17 (28.3\%) & $43(71.7 \%)$ & & $18(22 \%)$ & $64(78 \%)$ & \\
\hline $80+$ & 7 (2.9\%) & 35 (97.1\%) & & 7 (10.3\%) & $61(89.7 \%)$ & \\
\hline \multicolumn{7}{|l|}{ Race } \\
\hline Others & 59 (79.7\%) & 15 (20.3\%) & 0.001 & $59(71.1 \%)$ & $24(28.9 \%)$ & 0.000 \\
\hline Black & $88(73.9 \%)$ & $31(26.1 \%)$ & & $88(65.2 \%)$ & $47(34.8 \%)$ & \\
\hline White & $254(60.8 \%)$ & $164(39.1 \%)$ & & 255 (49.4\%) & $261(50.6 \%)$ & \\
\hline \multicolumn{7}{|c|}{ Pathological grade } \\
\hline Grade I & $37(38.5 \%)$ & $17(31.5 \%)$ & 0.140 & $37(56.1 \%)$ & $29(43.9 \%)$ & 0.318 \\
\hline Grade II & $70(69.3 \%)$ & $31(30.7 \%)$ & & $71(56.8 \%)$ & $54(43.2 \%)$ & \\
\hline Grade III & $40(53.3 \%)$ & $35(46.7 \%)$ & & $40(45.5 \%)$ & $48(54.5 \%)$ & \\
\hline Grade IV & $45(65.2 \%)$ & $24(34.8 \%)$ & & $45(57.7 \%)$ & $33(42.3 \%)$ & \\
\hline \multicolumn{7}{|l|}{ AJCC Stage } \\
\hline Stage I & 59 (92.2\%) & $5(7.8 \%)$ & 0.000 & $59(86.8 \%)$ & $9(13.2 \%)$ & 0.000 \\
\hline Stage II & $54(74.0 \%)$ & $19(77.8 \%)$ & & $54(65.1 \%)$ & $29(34.9 \%)$ & \\
\hline Stage III & $2(22.2 \%)$ & 7 (77.8\%) & & $2(20 \%)$ & $8(80 \%)$ & \\
\hline Stage IV & $6(66.7 \%)$ & $3(33.3 \%)$ & & $6(54.5 \%)$ & $5(45.5 \%)$ & \\
\hline \multicolumn{7}{|l|}{ T stage } \\
\hline $\mathrm{T} 1$ & $33(73.3 \%)$ & $12(26.7 \%)$ & 0.324 & $33(66 \%)$ & $17(34 \%)$ & 0.721 \\
\hline $\mathrm{T} 2$ & $121(81.8 \%)$ & $27(18.2 \%)$ & & $121(72.9 \%)$ & $45(27.1 \%)$ & \\
\hline T3 & 14 (70\%) & $6(30 \%)$ & & 14 (70\%) & $6(30 \%)$ & \\
\hline T4 & $1(50 \%)$ & $1(50 \%)$ & & $1(50 \%)$ & $1(50 \%)$ & \\
\hline \multicolumn{7}{|l|}{$\mathrm{N}$ stage } \\
\hline No & 155 (82\%) & $34(18 \%)$ & 0.001 & 155 (74.2\%) & $54(25.8 \%)$ & 0.006 \\
\hline N1 & 5 (38.5\%) & $8(61.5 \%)$ & & $5(35.7 \%)$ & 9 (64.3\%) & \\
\hline$N X$ & 9 (69.2\%) & 4 (30.8\%) & & $9(60 \%)$ & $6(60 \%)$ & \\
\hline \multicolumn{7}{|l|}{ M stage } \\
\hline MO & $163(81.1 \%)$ & 38 (18.9\%) & 0.003 & $163(74.1 \%)$ & 57 (25.9\%) & 0.001 \\
\hline M1 & $3(42.9 \%)$ & $4(57.1 \%)$ & & $3(30 \%)$ & 7 (70\%) & \\
\hline$M X$ & 3 (42.9\%) & $4(57.1 \%)$ & & $3(37.5 \%)$ & $5(62.5 \%)$ & \\
\hline
\end{tabular}


Table 1 The summary of MTTMJ patients' clinico-pathologic characteristics (Continued)

\begin{tabular}{|c|c|c|c|c|c|c|}
\hline \multirow[t]{2}{*}{ Variables } & \multicolumn{3}{|c|}{ Disease specific survival $(n=611)$} & \multicolumn{3}{|c|}{ Overall survival $(n=734)$} \\
\hline & Alive (\%) & Dead (\%) & $P$-value & Alive (\%) & Dead (\%) & $P$-value \\
\hline No & $31(40.8 \%)$ & $45(59.2 \%)$ & 0.000 & $31(33.7 \%)$ & $61(66.3 \%)$ & 0.000 \\
\hline Yes & $352(74.9 \%)$ & $118(25.1 \%)$ & & $353(62.8 \%)$ & $209(37.2 \%)$ & \\
\hline \multicolumn{7}{|c|}{ Radiotherapy } \\
\hline No & $305(70 \%)$ & $131(30 \%)$ & 0.000 & $305(57.3 \%)$ & $227(42.7 \%)$ & 0.005 \\
\hline Yes & $86(53.1 \%)$ & $76(46.9 \%)$ & & $84(45.4 \%)$ & $101(54.6 \%)$ & \\
\hline \multicolumn{7}{|c|}{ Chemotherapy } \\
\hline No & $295(67.5 \%)$ & $142(32.5 \%)$ & 0.122 & $295(55.2 \%)$ & $239(44.8 \%)$ & 0.673 \\
\hline Yes & 106 (60.9\%) & 68 (39.1\%) & & $107(53.5 \%)$ & 93 (46.5\%) & \\
\hline
\end{tabular}

small. Thus, it is impossible to perform epidemiologically relevant survival analysis. Here, we performed the first survival analysis regarding the age, sex and race of MTTMJ patients and found survival differences between these variables. Most importantly, we determined patient age as an independent prognostic factor for DSS and OS.
TNM/AJCC staging plays an irreplaceable role in head and neck cancer treatment. It is helpful to oncologists in determining treatment protocols and cancer prognosis [16]. However, in any previous studies, the TNM/AJCC staging was not used to evaluate the prognosis of MTTMJ. Most of the data on TNM staging are missing

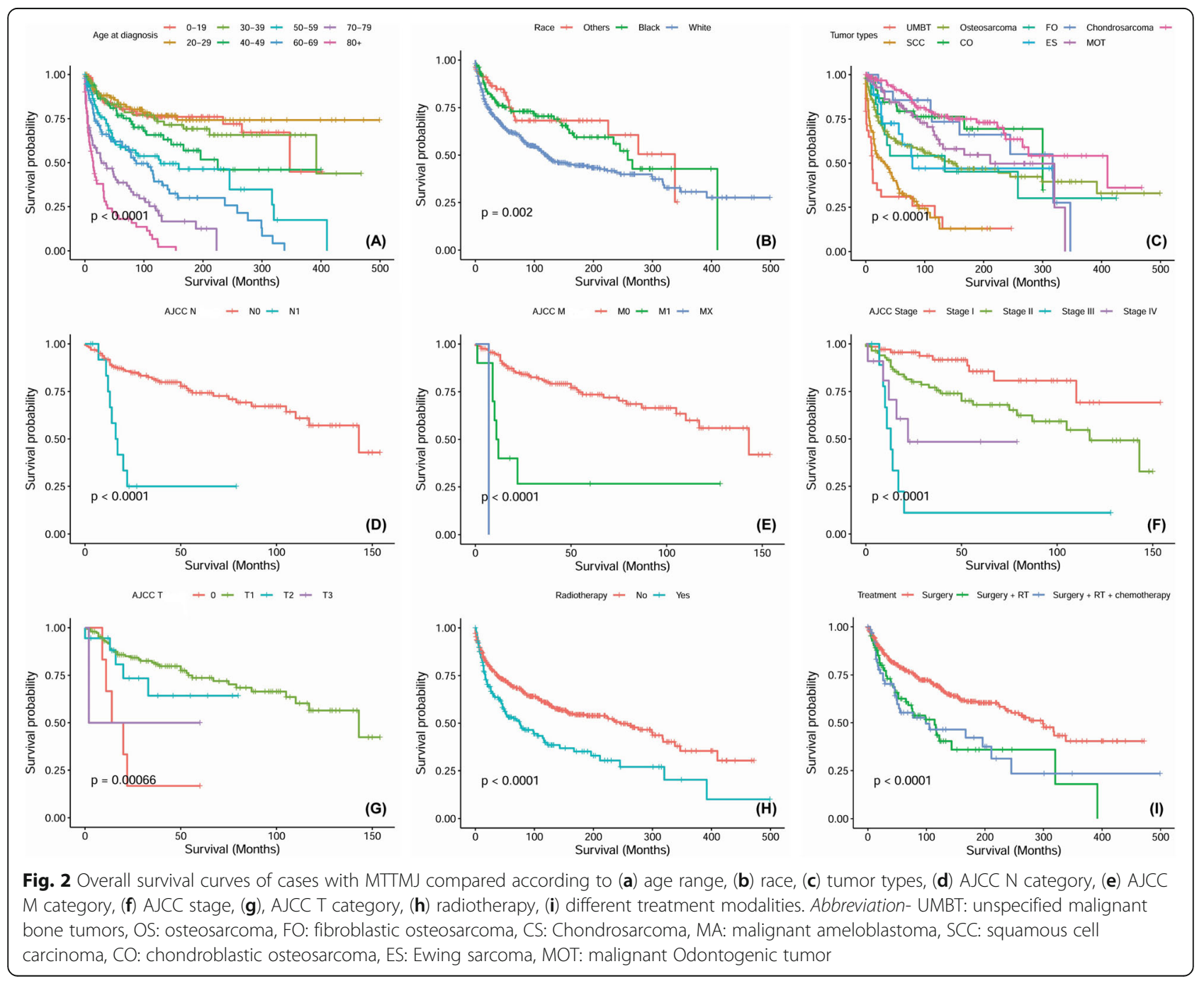




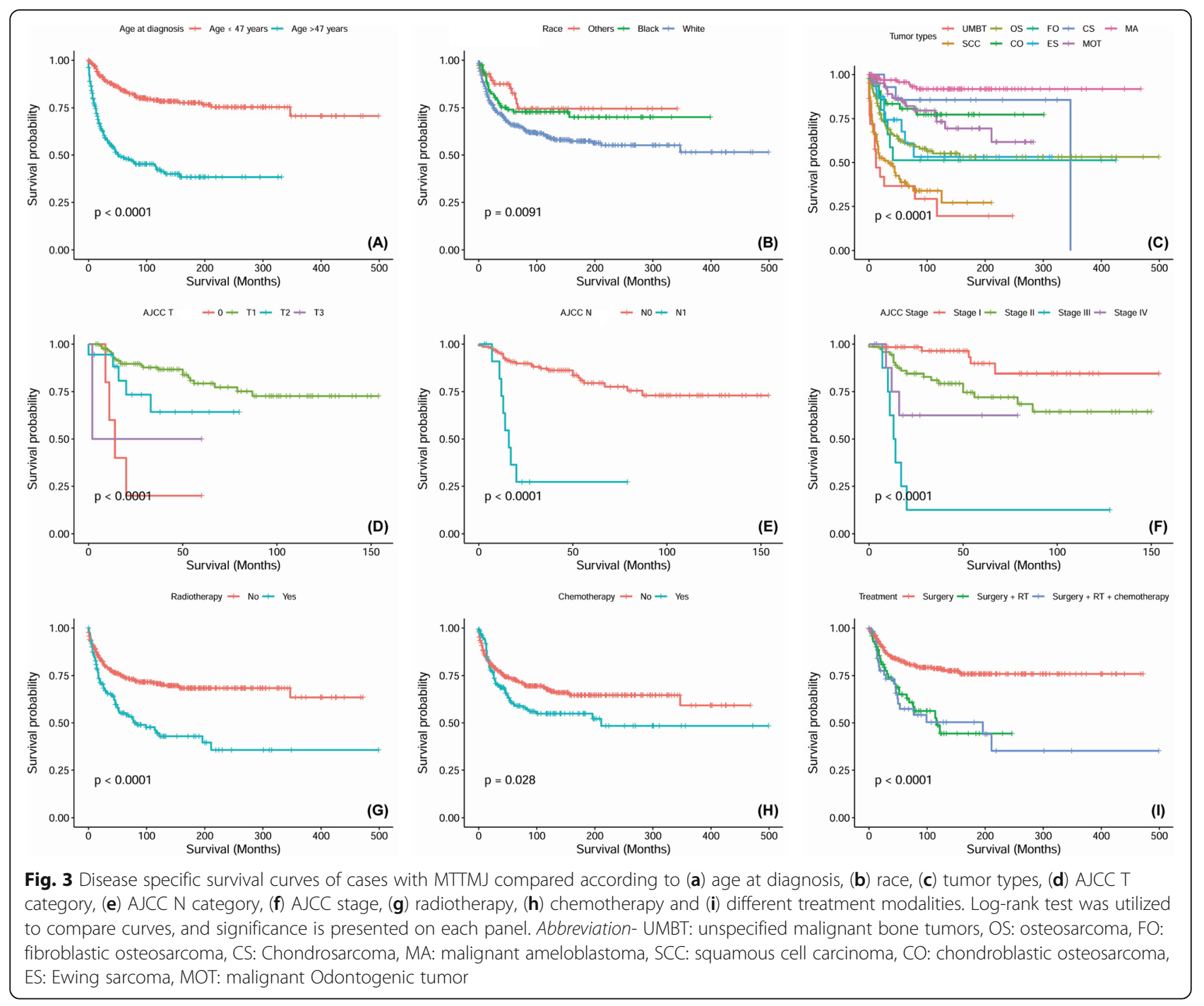

in our study. We evaluated survival using the available data, and typical differences were identified between these parameters. Among them, M category and AJCC stage were independently associated with DSS and OS. However, the conclusion is not very convincing. There are some confounding factors. First, the exact origin of the tumour is unknown. Second, all tumour types were analysed in a mixed fashion. These facts possibly weaken the conclusion since tumours of different origins and types have different biological behaviours and prognosis.

Surgical resection and reconstruction are the most important mainstay treatment modalities for solid tumours in the oral and maxillofacial region. Treatment information was missing in 172 patients, and the rest underwent surgery. The prognosis of patients treated with surgery alone was better than that of patients treated with surgery combined with chemoradiotherapy. This result illustrates the importance of complete surgical resection. However, this does not mean that chemoradiotherapy is ineffective for MTTMJ. Whether adjuvant chemoradiotherapy improves prognosis could not be concluded from these results. Chemoradiotherapy was implemented empirically for highly malignant pathological types, suspicious or positive surgical margins and advanced stage tumours. It is obvious that the prognosis of these patients was worse than that of those who received surgery alone. At this point, our analysis is largely consistent with previous reports [7] [17].

The anatomy of the TMJ includes the condyle, fibrous capsule, disk, synovial membrane, fluid and adjacent ligaments [18]. The anatomical content may be the possible explanation for the TMJ harbouring a myriad of malignant tumours [19]. However, the pathological tumour type did not demonstrate a specific prognosis. The largest percentage of tumours originates from the condylar process, and tumours originating from the rest of the TMJ structure are much fewer. Among various pathological tumour types, sarcoma and osteosarcoma 
variants account for more than $95 \%$ of the total study population. We selected nine most commonly seen pathological tumour types with a sample size of greater than 15 for survival analysis. Despite other factors, malignant ameloblastoma had the highest survival rate, and unspecified malignant bone tumours showed the worst prognosis.

Generally, because MTTMJ's signs and symptoms are similar to temporomandibular joint dysfunction, they may not receive sufficient attention [3]. Also, it is important to be aware of rare condition that could be misdiagnosed as a malignancy with the resulting unnecessary radical therapy. Therefore, the stomatologist must be alert, keeping in mind the occurrence of primary and metastatic tumours in the temporomandibular joint [5]. Like other solid malignant tumours in the head neck region, to deal with MTTMJ, early detection, early diagnosis and early treatment is fundamental. When clinical examination is suspicious, CT and MRI play an irreplaceable role in the early diagnosis and differential diagnosis of MTTMJ.

As a retrospective study, some limitations of this study and the SEER database should be acknowledged. Indeed, the SEER database provides the largest dataset for MTTMJ, which is one of its greatest advantages. However, the incompleteness of the data undermines its advantages. There are no data on clinical manifestations, and it is impossible to compare and discuss with previous reports. The exact orientation of the tumour remains unknown. However, it is certain that the majority of tumours originate from the condyle. Data on important variables, such as surgery types and TMJ reconstruction details, are incomplete. As superficial tumours, postoperative repair and reconstruction of the TMJ is more difficult than complete resection of the primary tumour. The quality of TMJ reconstruction has a great influence on the facial symmetry, function of the TMJ, occluding relation and postoperative quality of life. These factors are closely related to prognosis. Among the pathological types, squamous cell carcinoma accounted for a proportion of samples. The cervical lymph node metastasis rate of squamous cell carcinoma is relatively high. Whether neck dissection had been performed could not be determined in this cohort.

\section{Conclusions}

For the first time, we attempted to conduct a retrospective study on the epidemiological characteristics, clinicopathologic features, treatment, survival and prognostic factors of TMJ malignancy with the largest sample size. The study results demonstrate that MTTMJ mostly occurred in white people and that the median age at diagnosis was 47 years. There was no significant morbidity or mortality difference by sex. The patient's age and
AJCC stage were independently associated with OS and DSS. Despite the limitations, our study results are an important reference for the future diagnosis, treatment and prognostic assessment of TMJ malignancy. As a retrospective study with lower level of evidence, our findings in MTTMJ management requires validation in further multicenter, longitudinal, prospective, large cohort studies.

\section{Abbreviations \\ TMJ: Temporomandibular joint; MTTMJ: Malignant tumours of the temporomandibular joint; SEER: Surveillance, Epidemiology, and End Results; ICD-O-3: International Classification of Diseases for Oncology; AJCC: American Joint Committee on Cancer; SPSS: Statistical Package for the Social Sciences; OS: Overall survival; DSS: Disease-specific survival}

\section{Acknowledgements}

We acknowledge American Journal Experts (https://www.aje.com, AJE, Durham, NC, USA) for reviewing the manuscript for grammar consistency (ID: P616Z7WC).

\section{Authors' contributions}

ZY and AW contributed to the conception and design of the study; FY, CY and LF performed the experiments, MW and ML collected and analyzed data; FY, YL and HL wrote the manuscript; The authors reviewed and approved the final version of the manuscript.

Funding

None.

Availability of data and materials

Study data was publicly available in the SEER database.

Ethics approval and consent to participate

Not applicable.

Consent for publication

Not applicable.

\section{Competing interests}

The authors declare that they have no competing interest.

\section{Author details}

${ }^{1}$ Department of Oral \& Maxillofacial Surgery and Oral Biomedical Engineering Laboratory Shanghai Stomatological Hospital Fudan University, 356 Beijing East Road, Shanghai 200001, People's Republic of China. ${ }^{2}$ Department of Preventive Medicine, School of Public Health, Shanghai Medical College, Fudan University, Shanghai 200001, People's Republic of China. ${ }^{3}$ Department of Clinical Medicine, Shanghai Medical College, Fudan University, Shanghai 200001, People's Republic of China.

Received: 2 July 2020 Accepted: 16 September 2020

Published online: 06 October 2020

\section{References}

1. Yadav $S$, Yang $Y$, Dutra EH, Robinson JL, Wadhwa S. Temporomandibular joint disorders in older adults. J Am Geriatr Soc. 2018;66(6):1213-7.

2. Horswell BB, Sheikh J. Evaluation of pain syndromes, headache, and Temporomandibular joint disorders in children. Oral Maxillofac Surg Clin North Am. 2018:30(1):11-24.

3. Warner BF, Luna MA, Robert Newland T. Temporomandibular joint neoplasms and pseudotumors. Adv Anat Pathol. 2000;7(6):365-81.

4. Ren R, Mueller S, Kraft AO, Powers CN. Giant cell tumor of temporomandibular joint presenting as a parotid tumor: challenges in the accurate subclassification of giant cell tumors in an unusual location. Diagn Cytopathol. 2018;46(4):340-4.

5. Thoma KH. Tumors of the condyle and temporomandibular joint. Oral Surg Oral Med Oral Pathol. 1954;7(10):1091-107. 
6. Liu X, Zhou Z, Mao Y, Chen X, Zheng J, Yang C, et al. Temporomandibular joint anchorage surgery: a 5-year follow-up study. Sci Rep. 2019;9(1):1-10.

7. Hamza A, Gidley PW, Learned KO, Hanna EY, Bell D. Uncommon tumors of temporomandibular joint: an institutional experience and review. Head Neck. 2020;42(8):1859-73.

8. Arvidsson LZ, Mork-Knutsen BB, Hol C, Abrahamsson A-K, Ottersen MK Larheim TA. Other pathologic conditions of the TMJ. In: Imaging of the Temporomandibular joint. Cham: Springer; 2019. p. 291-300.

9. Bouloux GF, Roser SM, Abramowicz S. Pediatric tumors of the Temporomandibular joint. Oral Maxillofac Surg Clin North Am. 2018;30(1): $61-70$.

10. Al-Jamali JM, Voss PJ, Bayazeed BA, Spanou A, Otten JE, Schmelzeisen R. Malignant tumors could be misinterpreted as temporomandibular joint disorders. Oral Surg Oral Med Oral Pathol Oral Radiol. 2013;116(5):e362-7.

11. Mourad M, Jetmore T, Jategaonkar AA, Moubayed S, Moshier E, Urken ML. Epidemiological trends of head and neck cancer in the United States: a SEER population study. J Oral Maxillofac Surg. 2017:75(12):2562-72.

12. Oh KY, Yoon HJ, Lee Jl, Hong SP, Hong SD. Chondrosarcoma of the temporomandibular joint: a case report and review of the literature. Cranio. 2016;34(4):270-8.

13. Giorgione C, Passali FM, Varakliotis T, Sibilia M, Ottaviani F. Temporomandibular joint chondrosarcoma: case report and review of the literature. Acta Otorhinolaryngol Ital. 2015;35(3):208-11.

14. Garzino-Demo P, Tanteri G, Boffano P, Ramieri G, Pacchioni D, Maletta F, et al. Chondrosarcoma of the temporomandibular joint: a case report and review of the literature. J Oral Maxillofac Surg. 2010:68(8):2005-11.

15. Gallego L, Junquera L, Fresno MF, de Vicente JC. Chondrosarcoma of the temporomandibular joint. A case report and review of the literature. Med Oral Patol Oral Cir Bucal. 2009;14(1):E39-43.

16. Brandwein-Gensler M, Smith RV. Prognostic indicators in head and neck oncology including the new 7th edition of the AJCC staging system. Head Neck Pathol. 2010;4(1):53-61.

17. Shen Y, Ma C, Wang L, Li J, Wu Y, Sun J. Surgical Management of Giant Cell Tumors in Temporomandibular joint region involving lateral Skull Base: a multidisciplinary approach. J Oral Maxillofac Surg. 2016;74(11):2295-311.

18. Sakul BU, Bilecenoglu B, Ocak M. Anatomy of the Temporomandibular joint. In: Imaging of the Temporomandibular joint. Cham: Springer; 2019. p. 9-41.

19. Ramos-Murguialday M, Lasa-Menendez V, Ignacio Iriarte-Ortabe J, Couce M. Chondrosarcoma of the mandible involving angle, ramus, and condyle. J Craniofac Surg. 2012;23(4):1216-9.

\section{Publisher's Note}

Springer Nature remains neutral with regard to jurisdictional claims in published maps and institutional affiliations.

Ready to submit your research? Choose BMC and benefit from:

- fast, convenient online submission

- thorough peer review by experienced researchers in your field

- rapid publication on acceptance

- support for research data, including large and complex data types

- gold Open Access which fosters wider collaboration and increased citations

- maximum visibility for your research: over $100 \mathrm{M}$ website views per year

At $\mathrm{BMC}$, research is always in progress.

Learn more biomedcentral.com/submissions 